\title{
Correction to: Diminished Ovarian Reserve Chemotherapy-Induced Mouse Model: A Tool for the Preclinical Assessment of New Therapies for Ovarian Damage
}

\author{
Anna Buigues $^{1,2} \cdot$ Maria Marchante $^{1,2} \cdot$ Sonia Herraiz ${ }^{1,3,4} \cdot$ Antonio Pellicer ${ }^{1,3,5}$ \\ Published online: 10 November 2020 \\ (C) The Author(s) 2020
}

Correction to: Reproductive Sciences https://orcid.org/10.1007/s43032-020-00191-w

In the original article, Anna Buigues and Maria Marchante should have been listed as joint first authors.

Publisher's Note Springer Nature remains neutral with regard to jurisdictional claims in published maps and institutional affiliations.

The online version of the original article can be found at https://doi.org/ 10.1007/s43032-020-00191-w

Sonia Herraiz

sonia.herraiz@ivirma.com

1 IVI Foundation, Av. Fernando Abril Martorell, 106-TorreA-Planta1, 46026 Valencia, Spain

2 Department of Pediatrics, Obstetrics and Gynecology, School of Medicine, Valencia University, Valencia, Spain

3 Reproductive Medicine Research Group, IIS La Fe, Valencia, Spain

4 IVI-RMA Valencia, Valencia, Spain

5 IVI-RMA Rome, Rome, Italy 